\title{
Research on College English Teaching Model of Online Live Classes
}

\author{
Wu Huilan ${ }^{1, *}$ \\ ${ }^{1}$ English Teaching and Research Office, Beijing University of Chinese Medicine Dongfang College, Langfang, Hebei \\ 065000, China \\ *Corresponding author. Email: wu_hui_lan123@126.com
}

\begin{abstract}
The rapid development of information technology has provided more method choices for the reform of college English teaching. At the same time, due to the impact of the Novel Coronavirus in the spring semester of 2020, nationwide online live teaching has greatly promoted the form of "Internet + education". Based on the teaching practice of the author and other teachers in the same college, this paper analyses in details the common problems in the current college English live classes, proposes some suggestions for improvement, and finally discusses how to build college English "online and offline" blended teaching model based on online live courses in the future.
\end{abstract}

Keywords: online live classes, college English, common problems, suggestions for improvement, blended

teaching model

\section{INTRODUCTION}

The continuous development of new technologies such as the Internet and Artificial Intelligence, the rapid popularization of smart mobile terminals, and the widespread application of new media technologies have accelerated the reform of education methods in the information age among all the universities in China. Just at this time, the Novel Coronavirus suddenly broke out in China before the spring semester of 2020. The Ministry of Education decided to temporarily launch online teaching after the opening of various schools in the country, so online live teaching quickly entered the vision of every teacher. Without exception, college English live teaching has also become a normal teaching practice for a period of time, accelerating the pace of college English teaching reform. Based on the teaching practice of the author and other teachers in the same school, this paper will deeply explore the common problems of live teaching, improvement measures and the assumption of new teaching model of college English in the future, in order to promote the innovation of college English teaching methods and improve its teaching effect.

\section{COMMON PROBLEMS IN COLLEGE ENGLISH ONLINE LIVE CLASSES}

\subsection{Problems about the Role of Teachers and Students}

Although kinds of reform have been conducted in college English among all the universities in China, many teachers are still adopting traditional English teaching model, that is, the teacher is the centre of the classroom, and the students passively accept the learning content. In the large class in China, the teacher still plays the major role, mainly focusing more on providing English language knowledge for the students but to some extent ignoring whether students has understood or grasped the points of the class. Meanwhile, students just passively listen to the teacher and take some notes. All of these weaken students' learning enthusiasm and initiative to a certain degree and furthermore affects the overall teaching effect [6]. Under such circumstances, it is difficult to change the roles of teachers and students in the suddenly started live classes. Although teachers have realized that the role of teachers and students needs to be changed especially in the online live teaching, teaching practice cannot be effectively changed in a short time. Most time, the live class is still dominated by the teacher, which results in the imperfect teaching effect. 


\subsection{Incomplete Mastery of Teaching Technology}

In recent years, "online and offline" blended teaching has become a research hot topic in college English teaching reform, but most schools are in the early stage of experimentation [1]. Therefore, teachers and students haven't had a good grasp of new technologies. In this case, the sudden live classes make many teachers at a loss about online teaching technology. Although every school has conducted various trainings for teachers in a short time, there are still many problems in the actual teaching practice, such as insufficient grasp of the advantages and disadvantages of various online live broadcast platforms, lack of knowledge of the corresponding functions and specific operation procedures of some platforms. At the same time, due to the urgency of time, most schools only conducted simple trainings for teachers about network live broadcast teaching technology, but few technical training for students. Therefore, students' use of new technologies and platforms mainly depends on the guidance and help of the teachers, which further influences the effect of live teaching.

\subsection{The Difficult-Controlling Teaching Atmosphere}

The classroom of the online live teaching is mainly controlled by the teacher. Compared to the real class, teachers face much bigger challenges to create active classroom atmosphere and present good teaching effect in online live classes. If teachers don't know exactly the level of students' thinking and understanding of knowledge points in advance, it will be more difficult in an online live class to teach according to students' aptitude and adjust the teaching to suit the level of student acceptance [9]. In addition, teaching atmosphere in online live classes is also affected by the learner's concentration and learning awareness. According to the author's investigation, during the epidemic period, it was found that many colleges and universities implemented the same teaching time and teaching length as those in real school classes. As a result, many students are always distracted due to the too long teaching time. Thus, online live classroom teaching atmosphere is often difficult to control.

\subsection{Less Interaction between Teachers and Students}

Every educator knows the importance of communication and feedback. However, compared with traditional classrooms, teacher-student interaction in live classes is more limited [7]. First of all, the prerequisite for effective interaction is that both teachers and students have smooth network and can clearly transmit information. However, in actual live teaching, due to the influence of network signals, smooth video connection communication is not a common phenomenon. In most cases, only voice and text messages can be sent, which will take a long time and cannot meet the higher needs of oral English expression. In addition, there are obvious network delays on some live broadcast platforms, and the timely interaction between teachers and students in class is often blocked. In order to complete teaching tasks in the given teaching time, teachers often reduce some interactions.

\section{SUGGESTIONS FOR IMPROVING COLLEGE ENGLISH LIVE TEACHING}

\subsection{Repositioning Roles of Teachers and Students}

In the webcast classroom, the teaching approaches have changed. Accordingly, the views of teachers and students should also be changed, and both should not stick to the role positioning in traditional classrooms. First of all, teachers should fully change their role in the new teaching mode, transform traditional instilled teaching into guided teaching, and fundamentally emphasize the main role of students in classroom. At the same time, teachers should strengthen communication with students, help students to realize their own dominant position in the classroom and enhance self-study awareness, and then guide students to take the initiative to learn and actively participate in all the classroom activities. Only when students have established good learning concepts and habits and have changed from passive attitude to active attitude, can they make full use of various learning resources and improve their English learning level [8].

\subsection{Comprehensive Integration of Traditional and Modern Teaching Approaches}

The online live classroom deeply integrates the advantages of network resources, and it will be an indispensable teaching approach in the future [3] [6]. Therefore, from now on, teachers must learn to integrate traditional teaching approaches with modern teaching approaches, employ advanced teaching approaches to make up for the shortcomings of traditional teaching ones, implement experiential teaching model, and improve the teaching effect of online live classes. Online live classes actually present traditional classrooms in cyberspace. Almost existing online live teaching platforms have functions such as raising hands, taking notes, liking, chatting by private messages, and posting word, pictures and videos. Cooper's experiential learning theory believes that experiential learning is a continuous process based on experience [5]. Teachers not only provide new ideas, but also handle and modify the learners' previous experiences. In live classes, college English teachers no longer play their roles in simply instilling knowledge and helping students correct their mistakes. Most importantly, they should use audio- 
visual multimedia means to make some abstract concepts concrete, guide students to understand and absorb knowledge, and organize students to establish learning and helping groups. Then, learners can talk with each other in different spaces, promote each other and jointly improve the level of English learning.

\subsection{Scientific and Reasonable Arrangement of the Duration and Process of Live Teaching}

In any form of teaching design, every teacher must consider students' concentration and participation, which are even more critical for the design of online live classes [10]. With the increase of teaching time, students' concentration and participation will show a downward trend. Therefore, scientifically and reasonably arranging teaching time is the premise of efficient live classes. First of all, the live classes should not copy the actual teaching time in the classroom, and should be shortened timely. Teachers focus more on the key points or the difficult points during the online live classes. Other tasks can be done offline before and after the class. In addition, the author believes that knowledge points and task points should appear alternately in the process of live teaching. Research proves that ordinary people's attention can be maintained for a maximum of 20 minutes, and people's attention in online courses may be even lower, so teachers should grasp the rhythm of the classroom and reasonably arrange the frequency of knowledge points and task points. For example, teachers can centre on explaining certain language points for 15 minutes, and then interact with students through some tasks for 5 minutes, which can be made into several cycles in the whole class.

\subsection{More Effective Interaction}

College English teaching is a kind of foreign language teaching, in which the teaching content contains a lot of new language knowledge [11]. During the live teaching process, teachers must articulate words clearly, speak at a proper speed, and timely adjust the teaching schedule according to the network conditions. The key information can be displayed by means of PPT and screen. In addition, in online live teaching, teachers should design a variety of class activities to stimulate students' learning interest and make timely switchovers to avoid entering a vacant waiting state during the interactive link. They also should present more information in time according to students' feedback and control well the time of interaction to ensure the smoothness of the classroom. Moreover, teachers should timely sum up the key points and give advice during the teaching process, guide students to follow the teacher's thinking, use new teaching methods to create interesting teaching situations, and stimulate students' consciousness of participation and autonomous learning.

\section{CONSTRUCTION OF "ONLINE AND OFFLINE" BLENDED TEACHING MODEL OF COLLEGE ENGLISH BASED ON ONLINE LIVE COURSES}

Based on the development of computer technology and 5G network and the online live teaching practice during the epidemic, college English teaching in the future is bound to generally employ the "online and offline" blended teaching model based on online live courses [2]. The author suggests that this teaching mode be specifically divided into the online live teaching and guiding stage, offline classroom teaching stage, and comprehensive teaching evaluation stage.

\subsection{Online Live Teaching and Guiding Stage}

Online live teaching emphasizes on explaining specific knowledge, guiding learning methods, and preparing for in-depth classroom teaching [10]. Teachers need to teach and explain the difficult language knowledge during the live classes, and the students will display and communicate in English. If students are confused, they can input words in the discussion area at any time. After seeing the students' feedback, teachers can directly communicate and answer to help students find the correct learning method. After the online live lessons, the teacher assigns homework and shares learning materials. If students have doubts or do not participate in the live classes due to special circumstances, they can spend their spare time to watch the live playback. In addition, a live Question \& Answer classroom can be opened to facilitate the interaction between teachers and students, and it is also helpful for teachers to understand and master the knowledge level of students, and furthermore adjust the content of the next live class and offline classroom teaching [4].

\subsection{Offline Classroom Teaching Stage}

Offline classroom teaching focuses on answering questions, improving students' practical ability in English, and broadening students' horizons. From the perspective of the whole unit, teachers expand the overview of thematic knowledge, invite famous teachers or foreign teachers to give lectures, and enhance students' learning interest. In terms of ability improvement, after demonstrations and explanations, teachers may ask students to finish some difficult tasks and then teachers correct their mistakes immediately. At the same time, teachers can organize students to study in teams, and conducts discussions around topics. And then with topics the starting point, teachers help students break the isolated knowledge system, think deeply and activate knowledge, so as to improve their ability of learning and thinking and assist them to achieve unity of language knowledge and practice. 


\subsection{Comprehensive Teaching Evaluation Stage}

The teaching evaluation of blended teaching model should focus on the growth of learners, and teachers should implement an evaluation system combining quantitative evaluation and qualitative evaluation [4] [6]. Based on the online live courses, college English "online and offline" blended teaching model should try to adopt developmental teaching evaluation, design a multi-dimensional evaluation system, and conduct flexible teaching evaluation, instead of concentrating solely on test scores.

\section{CONCLUSION}

The form of "Internet + education" is an inevitable requirement of educational development in the new era [2]. Due to the promotion of online teaching during the epidemic, the integration of online live classes and traditional classrooms is an inevitable trend of blended college English teaching model in the future. Employing new type of teaching mode does not mean that teachers need to abandon the traditional teaching in essence, but how to better integrate online live classes and offline classroom is a question worth thinking about. There is a long way to go to build perfect platforms for live teaching, and use this new blended teaching model well.

\section{REFERENCES}

[1] Gan Ye, Research on Blended College English Teaching Based on Online Live Classes [J], Educational Academic Monthly, 2017 (11): 79-87.

[2] He Kekang, New Development of Educational Technology Theory from Blending Learning [J], Journal of China National School of Education Administration, 2005 (09).

[3] Wang Zhu, Research on College English Blended Teaching Model under "Internet +" [J], Contemporary Educational Practice and Teaching Research, 2020 (04): 3-4.

[4] Yang Shanshan, Long Qiuju, Research on "Online and Offline" Mixed Teaching Model of College English Based on Online Live Classes [J], Journal of Bai Se University, 2019, 32 (06): 135-140.

[5] David Cooper, Experiential Learning: Let Experience Become the Source of Learning and Development [M], Shanghai: East China Normal University Press, 2008: 2.

[6] Cai Zhichao, Cao Tianhong, Zeng Jianjun, Zheng Xiaofang, Research and Analysis of Webcasting
Teaching Mode [J], Western Quality Education, 2017, 3 (14): 126-128.

[7] Yang Jiaoshi, Ma Qian, Research on the Flip Classroom Teaching Model Based on Superstar Learning Link [J], Chinese and Foreign Entrepreneurs, 2020 (08): 211.

[8] Chen Ming, Discussion on College English Teaching Mode in the "Internet +" Era [J]. Journal of Kaifeng Institute of Education, 2018, 38 (05): 72-73.

[9] Nie Zhaoyu, Live Video Teaching: the New Situation of "Internet + Education" [J]. Software Guide (Education Technology), 2019, 18 (09): 80-81 + 86.

[10] Wang Xue, Zhou Pu, Liu Shuya, Construction of Blended Live Broadcast Teaching Model under Core Literacy Concept [J]. Modern Primary and Secondary Education, 2019, 35 (12): 22-28.

[11] Liu Jia, "Live Broadcasting + Education": Exploring New Forms and Values of "Internet +" Learning [J]. Journal of Distance Education, 2017 (01). 